\title{
Tilsa en el aventurado camino de Noé Delirante de Arturo Corcuera ${ }^{1}$
}

\author{
Tilsa in the adventurous path of Noé Delirante by Arturo Corcuera
}

\author{
Ana María Rocha Puente ${ }^{2}$ \\ Investigadora independiente - Lima, Perú \\ https://orcid.org/0000-0002-6561-9846
}

\section{RESUMEN}

A través de este artículo, nos acercamos a un aspecto de la vinculación creativa entre dos artistas relevantes de la cultura peruana contemporánea: Tilsa Tsuchiya, pintora, y Arturo Corcuera, poeta, quienes desarrollaron una productiva amistad traducida en la colaboración artística. Para ello, y a modo de muestra, hemos recurrido a un poema del libro Noé delirante de Corcuera y la respectiva ilustración realizada por Tsuchiya, buscando encontrar - a través del análisis formal y semántico-las relaciones de significación que las conectan.

\section{Palabras clave}

Noé delirante, Arturo Corcuera, Tilsa Tsuchiya, poesía, ilustración, relación texto e imagen, colaboración artística.

\section{ABSTRACT}

This article addresses an instance of the creative link between two important artists in contemporary Peruvian culture: painter Tilsa Tsuchiya and poet Arturo Corcuera, who forged a productive friendship which translated into artistic collaboration. Through the formal and semantic analysis of a poem from the book Noé delirante by Corcuera and its respective illustration made by Tsuchiya, the article seeks to find the relationships of signification that connect both works.

\section{Keywords}

Noé delirante, Arturo Corcuera, Tilsa Tsuchiya, poetry, illustration, text-image relationship, artistic collaboration.

\section{(c) $\mathbb{D} \Theta \Theta$}

Cualquier uso que se haga

de este artículo debe incluir:

Autor / Título original de la publicación / ISSN.

1. Este artículo se basa en la tesis realizada en el año 2012 para optar al grado de Licenciatura en la Universidad Católica del Perú, Facultad de Letras y Ciencias Humanas, denominada El discurso poético y el discurso visual en Noé delirante de Arturo Corcuera.

2. Educadora. amrochap@gmail.com 


\section{INTRODUCCIÓN}

¿Por qué un poeta integra ilustraciones de otro creador en su obra? La respuesta puede orientarse a la búsqueda de una intensión totalizadora del mensaje, a la curiosidad por ver su obra reflejada en otro lenguaje, o quizá, a un auto desafío por encontrar una respuesta al enigma de sus palabras. Estas y muchas hipótesis son posibles. Lo cierto es que el libro de poemas Noé delirante de Arturo Corcuera, ha tenido en sus más de 50 años de existencia, ilustradores con enfoques estilísticos y modos de interpretación diversos. Entre ellos, fue la pintora Tilsa Tsuchiya, quien contribuyó con la mayor cantidad de imágenes, todas ellas de profunda significación y utilizando su muy personal estilo.

La relación entre la creación literaria y las artes plásticas (en ese caso el dibujo) puede llegar a tener interesantes matices. Para el lector, este tipo de colaboración implicará una renovada forma de enriquecer su mirada y su pensamiento. Para los artistas, supondrá nuevos caminos de entender los alcances de su propia producción.

A partir de este horizonte, el presente trabajo se propone una aproximación al discurso de un poema de Corcuera y a la manera en que Tsuchiya lo interpretó visualmente, estableciéndose correspondencias quizá insospechadas para ambos. Y eso es el arte, el juego con lo inesperado.

\section{DESARROLLO}

Todo texto $-y$ aún más uno de naturaleza poética-es un espacio de contingencias, en el que la palabra como totalidad discursiva es un terreno fértil para la interpretación de los lectores. S. Mallarmé ya había hablado respecto al texto poético como juego de posibilidades $^{3}$, y U. Eco, en su obra Lector in fabula, transmite cuál es la función del lector como principio activo en la lectura: un texto está sometido a la dinámica de la interpretación del lector, quien en su quehacer encontraría y recrearía mundos quizá imprevistos por el escritor (Eco, 1979); así, la propuesta de lectura de un poema implica riesgos a los que un escritor se lanza con diversos grados de conciencia y de manejo o dominio de su producción. En este contexto, el acto de incluir ilustraciones de otro artista acompañando su obra representa -tanto para un poeta como Arturo Corcuera (Trujillo, 1935Lima, 2017) como para el lector- un paso más en el aventurado y sorprendente proceso de creación y recepción de un discurso.

Noé delirante, libro que recibió en el 2006 el Premio Casa de las Américas, tuvo su primera edición en 1963 con ilustraciones de Félix Nakamura ${ }^{4}$. Ya desde entonces, el autor demostró una constante disposición para que esta obra funcione, en distinta medida, como texto ilustrado, con imágenes visuales que pueden ser comprendidas en un sentido tradicional como acompañamiento

3. Mallarmé, Stéphane (Francia,1842-1898) había publicado Una tirada de dados nunca abolirá el azar (1897). Escribe Mallarmé: "El poeta deja la iniciativa a las palabras, al impacto de sus diversidades puestas en movimiento. Las palabras se encienden a través de reflejos mutuos como lo hace una llama al caer sobre piedras preciosas." Citado por E. Kahler, E. (1969), p.84.

4. Para esta primera edición contó con el apoyo del poeta Javier Sologuren y su reconocida editorial La Rama Florida. 
al texto, usualmente subordinándose a él. Sus diversas reediciones con distintos ilustradores durante más de 50 años nos lo demuestran ${ }^{5}$.

Entre quienes acompañaron con sus obras gráficas el largo camino de Noé Delirante, fue la pintora Tilsa Tsuchiya (Supe, 1929 - Lima, 1984), quien estuvo más presente. Aparece en la tercera edición de 1971 (Corcuera,1971) que es la fuente del presente artículo. El aporte gráfico de Tilsa se mantendrá durante varias reediciones ${ }^{6}$. Destaca también el hecho de ser quien contribuyó con la mayor cantidad de ilustraciones.

Cuando Tsuchiya participa con sus dibujos, era ya una artista reconocida. Tenía en su haber una muestra en el Instituto de Arte Contemporáneo (1968) y había sido merecedora de múltiples reconocimientos, entre ellos, del Premio Tecnoquímica (1970). La artista estaba desarrollando ese mundo complejo y misterioso de seres fusionados o en estados de transmutación que la caracterizaría, así como modelado su lenguaje pictórico de atmósferas brumosas y sutiles transparencias. Ella, tenía ya una voz, un discurso propio que instaura en el mundo de Noé delirante, obra que, si bien la inspiró, a su vez recibió el aporte enriquecedor y de propia autonomía de esta artista (figura 1).

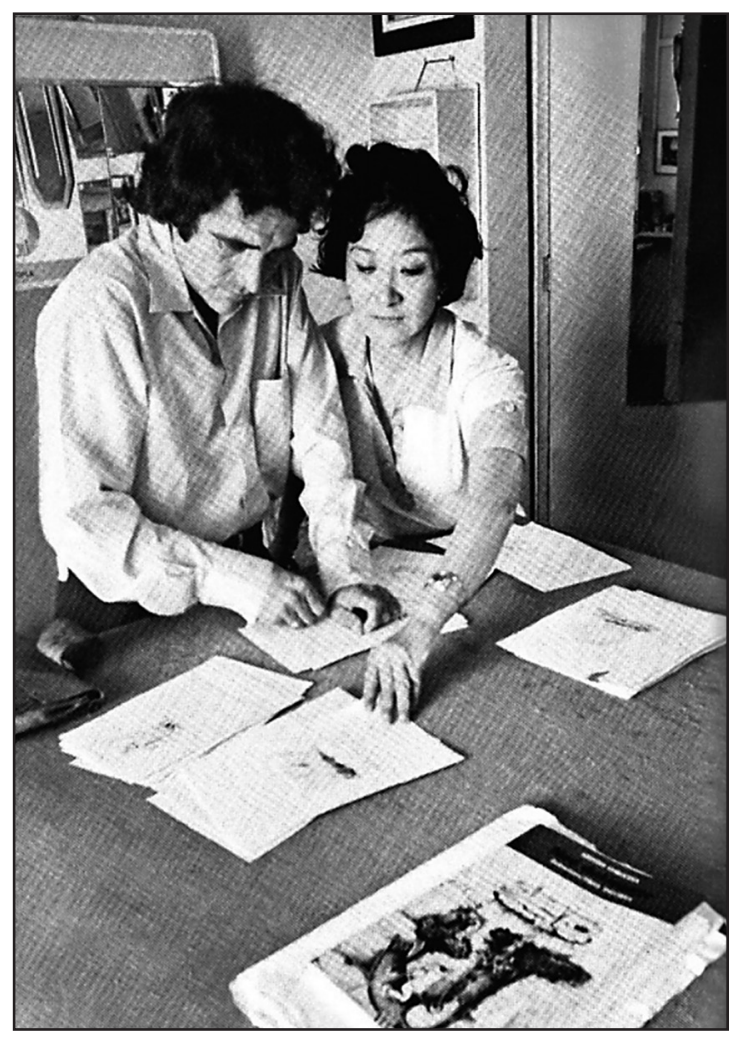

Figura 1. Tilsa Tsuchiya y Arturo Corcuera elaborando la edición de Noé delirante de 1971.

Fuente: Tsuchiya, T. (2010)

Sobre el origen de esta colaboración, el mismo autor de Noé lo explica en una entrevista:

... la conocí personalmente por intermedio de Winston Orrillo: fue a través de él que Tilsa se enteró de que yo había terminado un libro de poemas, Noé delirante, en su primera versión, y le había gustado mucho y quería ilustrarlo. Me llegó el mensaje y claro, como soy un poco descuidado, pasaron los días y no la llamaba,

5. En las múltiples reediciones participaron sucesivamente como ilustradores: F. Nakamura, Tilsa Tsuchiya, Gabriel Lefevbre y Rosamar Corcuera, hija del poeta. La última reedición ha sido en el 2018.

6. Al parecer los dibujos de Tilsa Tsuchiya estuvieron presentes durante seis reediciones más. 
hasta que me mandó decir que estaba próxima de viajar a París y que si no le llevaba los originales no iba a poder hacerlo después. Le mandé finalmente los originales. Pensé que me iba a hacer... no sé, cuatro, cinco dibujos, pero me ilustró la mitad del libro. Cuando terminó quedé impresionado con el material. Se lo mostré a un editor, Carlos Milla Batres, y él me dijo: "tiene que hacerte todo el libro". Y él fue y le habló. Le dijo que iba a ser una gran edición y ella aceptó. (Corcuera, 2014, "Cuál fue la primera impresión," párr. 1) ${ }^{7}$.

Fueron 72 poemas que Tsuchiya ilustró en la edición de 1971, lo que permitió realizar una secuencia alternada entre poema e imagen a través de todo el libro.

Si bien no se ha realizado aún un estudio exhaustivo de la interacción de la totalidad de textos e imágenes ofrecidos por estos dos artistas en aquella edición, queremos plantear, a través del análisis de uno de los poemas y de la ilustración correspondiente, un acercamiento que permitirá vislumbrar la conexión entre los discursos puestos en juego, así como la relación de significación que se establece entre poema e ilustración. Y de esta manera, además, esbozar una apreciación sobre las implicancias de la colaboración artística entre dos creadores.

\section{Hacia el análisis}

Y. Lotman consideraba que tanto un poema como una ilustración pueden ser enfocados como textos enmarcados dentro de lenguajes artísticos con características propias (Lotman, 1978) ${ }^{8}$. Ellos buscan semantizar de una manera particular el mundo. Se puede precisar que, si el poema lo hace a través de la palabra, del tiempo, de la condensación verbal, de la recuperación de la materia significante e incluso de la disposición del poema en el espacio de la página, el dibujo lo hará a través del grafismo, de su estructura, de la simultaneidad, de su relación con el espacio formato y de la factura de la línea, incluyendo otros recursos gráficos utilizados.

Debido a las características tan diferentes de los lenguajes, el pasaje de sentidos de un poema a su ilustración implicaría, ya desde una primera instancia, una transformación en la significación de aquello ilustrado. Veremos en este ejemplo, texto e ilustración de la Fábula del árbol que no vuela, los resultados suscitados.

7. En esta entrevista A. Corcuera refiere detalles del proceso de su amistad con T. Tsuchiya.

8. Lotman define un lenguaje como un sistema comunicativo que implica un vocabulario, así como reglas combinatorias, considerando que es un concepto aplicable al teatro, el cine, la música o la pintura, entre otras artes que permiten la interacción emisor y receptor. 


\section{Sobre el poema}

\section{Fábula del árbol que no vuela}

\section{Otorgas}

pájaros,

castañas,

sombra

quemándote las ramas,

obrero del encinar.

¿Por qué con tantas

alas

no intentas volar? ${ }^{9}$

(Corcuera, 1971, p. 97)

El texto es planteado a través del título como una fábula que tiene como protagonista a un personaje árbol caracterizado por el no-vuelo. Recuerda por su brevedad, al haiku japonés, y por su disposición espacial -vista en el conjunto de las páginas abiertas- a un caligrama, sugiriendo la silueta de un árbol: el poema es el "tronco" y el título, la "copa" que cobija gráfica y semánticamente al texto. El espacio en blanco de la página es el entorno del poema, que configurará el silencio simbólico que lo rodea, pero será también el soporte que acoja y asegure, mediante la compaginación dada, la vecindad entre poema e imagen.

Una primera lectura del poema sugiere una historia breve y concisa, pero que irá mostrando a través del análisis una gran densidad en su significación. Se plantea como un pequeño monólogo, voz de un narrador omnisciente (¿Noé?), quien conjuga su función de observador con el de crítico respecto al protagonista de la historia.

En la primera estrofa, en un aparente diálogo con el personaje árbol, realza la personalidad de este, caracterizándola como generosa, pues otorga a otros alimentación, descanso y solaz; todo ello a costa de su autosacrificio. Lo define metafóricamente como "obrero del encinar" configurando así la esencia de sus atributos precisados en un paradigma o modelo de ser que el árbol representa: masculinidad, resistencia y servicio a otros. Es una visión exaltante del obrero definido en un entorno natural como es el bosque de encinas.

Simultáneamente, la condensación verbal sugiere elípticamente la presencia de un paisaje y un bosque, un locus amoenus donde el personaje cumple su central $\mathrm{y}$ generosa función, cuya contraparte ambivalente es la presencia tácita del sol cuyo exceso de calor daña al personaje árbol.

En la segunda estrofa, que es muy breve, se produce un giro que incide en el cuestionamiento de la subjetividad del personaje árbol. El narrador lo increpa por no dar rienda suelta a las "alas" que posee como personaje fabuloso y generoso. Se introduce así una ruptura en la "realidad" de la historia, que abre al lector una puerta a otro nivel de comprensión del texto: una lectura a través del mito y del simbolismo.

M. Elíade hace un planteamiento sobre la función de axis mundi que puede tener el árbol, con su claro poder de vincular lo

9. Esta es la disposición tipográfica original del poema; no se ha colocado comillas para tratar de mantener el efecto visual original. En esta edición de 1971 el poema se ubicaba en la página derecha del libro y la ilustración en la página izquierda. 
terrenal con lo alto, espacio inaccesible al hombre como tal y que pertenece a lo sobrehumano (Elíade, 1981). Ello sugeriría que este árbol es un ser que ha perdido su capacidad simbólica de elevarse y trascender. Prueba quizá de una naturaleza quebrantada, susceptible de ser lastimada y destruida.

Esta lectura puede complementarse con la referencia de que en las mitologías europeas la encina tiene poderes mágicos y relación con divinidades importantes. Como ejemplo, dice J. E. Cirlot que, este es un árbol consagrado a Júpiter simbolizando la fuerza y la duración, que atrae más que otros al rayo (Cirlot, 2003). Se marca así el concepto de resistencia de la encina frente al tiempo y a las fuerzas cósmicas destructivas.

La densidad semántica de términos como volar y alas presentes en la segunda estrofa, constituyen el sustrato de otra variable interpretativa: el tema de los límites del vuelo poético, los conflictos del poeta y el trance de la inspiración, temas ya tratados desde los griegos y que los poetas occidentales han continuado con variantes múltiples. Así, ya Platón hablaba de la esencia sagrada y alada del poeta (Soares, 2010). También Ch. Baudelaire plantea en su poema Elevación este conflicto vital del poeta entre una vida apesadumbrada y la posibilidad de alcanzar lo alto (Baudelaire, 1972).

Desde esta visión, el poema sería una alegoría del conflicto creativo del poeta: otorga dones al mundo, pero como este personaje árbol, su cotidianidad y razón lo pueden amarrar a lo terreno y su espíritu no alcanza el vuelo creativo. La luz quemante de la inteligencia racional en lugar de iluminar al poeta, lo destruye, lo oscurece; es un ancla para el vuelo poético, pues la creación y la trascendencia piden la locura $\mathrm{o}$, en todo caso, la ruptura con lo real cotidiano.

\section{Sobre la ilustración}

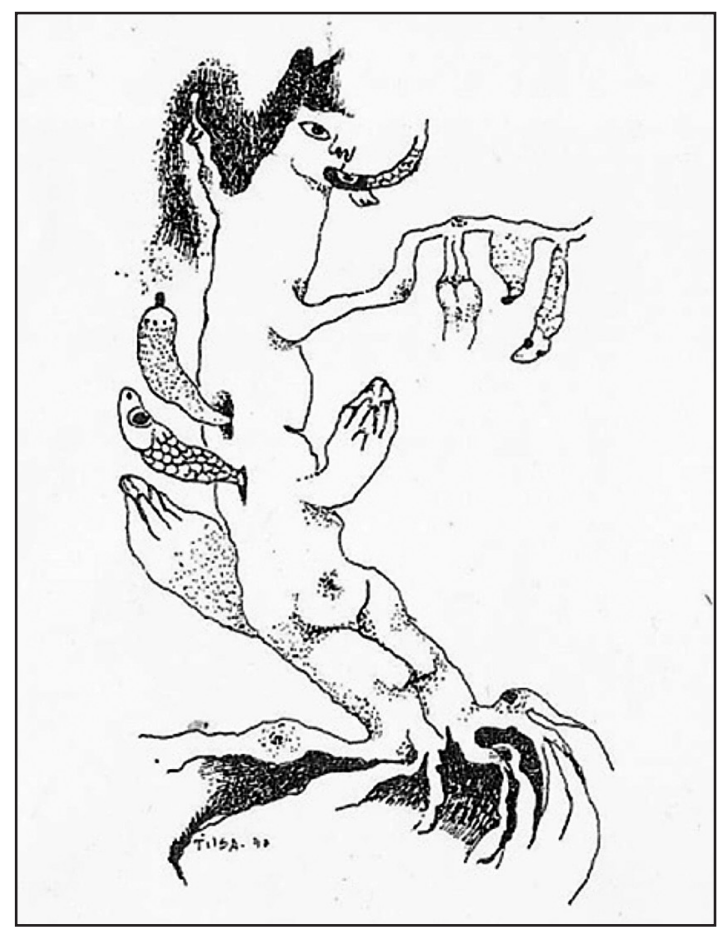

Figura 2. Ilustración de Tilsa Tsuchiya para el poema Fábula del árbol que no vuela de A. Corcuera, 1971, p. 96

Tilsa como pintora tenía una técnica sutil y orientada a la transparencia que traducía muy bien un mundo de transmutaciones sugeridas y ciertamente únicas, apartado del realismo descriptivo y directo. En esta ilustración opta por la técnica del dibujo a plumilla utilizando una delgada línea acromática y orgánica para construir el contorno de la figura ubicada en el centro de la página. La línea se complementa con la aplicación de un tenue puntillismo y tramas gráficas, cuyas funciones son la 
creación de texturas, el logro parcial de grises y leves efectos de volumen. El uso exclusivo del contraste negro y blanco -negro de la tinta y blanco del papel- crea una imagen de mediana iconicidad, sobria en sus recursos y sintética en sus resultados que, además, conecta acertadamente con la idea de fragilidad y sutileza del mundo sugerido.

Se muestra una figura con características humanas y arbóreas. La inconclusa cabeza, de nariz platirrina muestra una boca de la que -no se sabe si emerge o se introduceuna forma alargada y semicurva con texturas semejantes a las escamas de un pez o de una serpiente, sugiriendo rasgos característicos de la cultura paracas ${ }^{10}$.

En su desnudez, la figura muestra la presencia del pubis que remite a una esencia femenina, realzada por una línea de contorno ondulante y delicada. El cuerpo elongado y ligeramente curvo parece impulsarse con las piernas buscando elevarse, aunque se ve limitado por fuertes raíces que se lo impiden. Del largo tronco se generan ramas y seres-algunos pisciformes, otros simplemente orgánicos, frutos semejantes a senos- que se orientan a través de diagonales hacia lo alto; el tronco termina en lo que pareciera una cabellera follaje de una oscuridad comparable a la tierra que la detiene. Se plantea así una ambigüedad formal que propone una incógnita al receptor y suscita la sensación de estar ante una entidad, mujer-árbol, que integra a seres en proceso de formación o fusión.
Vista la figura en su conjunto, es destacable el contrapunto creado por las diagonales dirigidas hacia lo alto y unas pocas orientadas hacia abajo, complementadas por las oscuridades estáticas de la tierra y la cabellera. De acuerdo con V. Kandinski (1971) ello tiene gran importancia estructural en la imagen. Este gran artista explicaba que eran las tensiones compositivas la esencia de una composición. De esta manera, visual y silenciosa, y teniendo como fondo el espacio en blanco, mundo de posibilidades, Tilsa transmite el conflicto del vuelo del personaje femenino: una mujer-árbol, generadora y sustentadora de seres. Complementando esta lectura del dibujo, su estructura arbórea remite nuevamente al axismundi, en busca de elevación y acercamiento a lo alto y de alusiones al dadivoso árbol del paraíso cristiano.

El tema de la mujer generadora fue plasmado por Tilsa en importantes cuadros como "La gran madre" de 1972. Constituyó un tema de suma importancia en su obra que sintetizaba su interés por el mundo mítico en el que confluían asociaciones con antiguas representaciones de diosas como Artemisa o Deméter, y reminiscencias prehispánicas, como ya se ha indicado. M. Elíade (2014) nos ayuda a comprender el simbolismo de esta figura definiendo a la tierra como Genetrix universal quien se autoinmola en soledad. La explicación de Elíade permite decodificar el aislamiento de la mujer-árbol como parte de una visión en la que ella en soledad, aúna sus fuerzas para la procreación y sustentación de los seres de la naturaleza.

10. La artista manifestó su interés por las antiguas culturas peruanas:”Mi pintura me sitúa con una constante que es el hombre, la cultura, el ancestro, la recuperación del espíritu de nuestros antiguos creadores: los chavín, los paracas,los mismos incas...”. Entrevista por A. La Torre, A.,1976, p.46.). 
Sin embargo, una mirada a la configuración de este personaje dentro del conjunto del mundo creado por esta artista y de su repertorio visual general, remite, además, a la presunción que estamos ante una figura de sugerencias fálicas como ya ha sido acotado por M. Radulescu (19961997) $)^{11}$. Al simbolismo ya mencionado del árbol y de la Genetrix universal, se sumaría una intensión que enfatiza -a través de las formas gráficas que son la herramienta del dibujante, la idea de la fecundidad totalizadora, que integra la naturaleza femenina con elementos masculinos, enmarcado todo ello por su manifiesto interés por lo mítico. Por lo demás, la intención de reconocimiento e identificación de este dibujo como obra de su repertorio estaría incluso marcada por su firma que aparece en la zona inferior del dibujo.

\section{Los vasos comunicantes}

En el libro, la ilustración y texto se encuentran frente a frente -una a la izquierda del lector y el otro a la derechaestableciendo un eslabonamiento visual que permite percibirlos simultáneamente, constituyendo en el espacio de las páginas abiertas una geografía que el lector puede recorrer con libertad, probablemente de un modo aleatorio y lúdico, también con detenimiento hasta encontrar los conectores de significación subyacentes entre ellos.

Aquí se ha propuesto, a través de este somero análisis, una lectura e interpretación de dos "textos", -el poema Fábula del árbol que no vuela de Arturo Corcuera y aquel de la ilustración de Tilsa
Tsuchiya- entendiéndose que ambos son contenedores de dos discursos poéticos con sus propias características y que ponen en juego valores de significación complejos en los que la elipsis verbal y visual funcionan abriendo campos a la interpretación.

El poema, presentado con una disposición caligramática, permite al lector la construcción de un tejido de significación que propone como paradigma a un personaje árbol, masculino y generoso. Pero más allá de la historia inmediata del árbol, se alude y poetiza el conflicto de la posibilidad de transcendencia de la naturaleza y del artista. La entrega del personaje árbol, en un plano simbólico, no lleva más que a un límite y el alto espacio añorado no se alcanza.

La ilustración mantiene en un primer nivel la conexión semántica, al graficar -mediante formas de asociación icónica- lo arbóreo del personaje y su intención de vuelo. Pero una lectura analítica de la imagen muestra que la ilustradora ha realizado un cambio profundo: el paradigma propuesto por el poema ha sido transformado, mostrándose ahora en su versión femenina, como mujerárbol. Y este personaje creado por la artista se asocia directamente al repertorio visual de su obra general.

Aparece, así, la diosa madre de reminiscencias ambiguas que integraría dentro de lo femenino asociaciones masculinas, convirtiéndose en una entidad totalizadora primordial. 


\section{CONCLUSIONES}

Se podría concluir que la transposición de la significación del poema a la ilustración ha tenido un costo: la diferencia de paradigmas propuestos por ambos discursos. Sin embargo, su resultado no es negativo; por el contrario, ha contribuido a acrecentar la gama de posibilidades a interpretar por el lector y muestra cómo la colaboración entre dos artistas puede ser enriquecedora -como en este caso- cimentándose en la transmutación y el proceso, enalteciendo así el largo camino de Noé delirante. 


\section{REFERENCIAS}

Baudelaire, C. (1972). Las flores del mal. Buenos Aires: Ed. Losada.

Cirlot, J. E. (2003). Diccionario de símbolos. Madrid: Ediciones Siruela.

Corcuera, A. (1963). Noé delirante. Lima: Ediciones La Rama Florida.

Corcuera, A. (1971). Noé delirante. Lima: Ediciones Carlos Milla Batres.

Corcuera, A. (29 de setiembre de 2014). Tilsa Tsuchiya en el recuerdo de Arturo Corcuera. Entrevistado por Alonso Almenara. La Mula. Recuperado de https://redaccion.lamula. pe/2014/09/29/tilsa-tsuchiya-en-el-recuerdo-de-arturo-corcuera/alonsoalmenara

Eco, U. (1979). Lector in fabula. Barcelona: Lumen.

Elíade, M. (1981). Tratado de historia de las religiones. Morfología y dialéctica de los sagrado. Madrid: Ediciones Cristiandad.

Elíade, M. (2014). Lo sagrado y lo profano. Barcelona: Paidos.

Kahler, E. (1969). La desintegración de la forma en las artes. México: Siglo XXI Editores.

Kandinski, V. (1971). Punto y línea sobre el plano. Barcelona: Barral Editores.

La Torre, A. (1976). Los mitos de Tilsa. Entrevista a la artista. En: Tilsa Tsuchiya, Maestros de la pintura peruana. Lima: Ed. El Comercio.

Lotman, Y. (1978). Estructura del texto artístico. Madrid: Ediciones Itsmo.

Radulescu, M. (1996-1997). Tilsa Tsuchiya, una manera de ver. La casa de cartón de Oxy. Revista de Cultura. II Época, 10, 48 -63.

Rocha A. M. (2012). El discurso poético y el discurso visual en Noé delirante de Arturo Corcuera (Tesis de Licenciatura). Pontifica Universidad Católica del Perú, Facultad de Letras y Ciencias Humanas.

Soares, L. (2010). No existen los poetas, existen los hablados por la poesía. Confines [Buenos Aires], 26. Recuperado de http://rayandolosconfines.com/tradu7.html

Tsuchiya, T. (2010). Maestros de la pintura peruana. Lima, Perú: Punto y Coma Editores S.A.C.

Fecha de recepción: 10 de marzo de 2020

Fecha de aceptación: 3 de abril de 2020 